\title{
A Common Fixed Point Theorem in Metric Space under General Contractive Condition
}

\author{
Sunny Chauhan, ${ }^{1,2}$ Zoran Kadelburg, $^{3}$ and Sumitra Dalal ${ }^{4}$ \\ ${ }^{1}$ R.H. Government Postgraduate College, Udham Singh Nagar, Kashipur, Uttarakhand 244713, India \\ ${ }^{2}$ Near Nehru Training Centre, H. No. 274, Nai Basti B-14, Bijnor, Uttar Pradesh 246701, India \\ ${ }^{3}$ Faculty of Mathematics, University of Belgrade, Studentski trg 16, 11000 Beograd, Serbia \\ ${ }^{4}$ Department of Mathematics, Jazan University, Saudi Arabia \\ Correspondence should be addressed to Sunny Chauhan; sun.gkv@gmail.com
}

Received 30 April 2013; Revised 12 July 2013; Accepted 4 August 2013

Academic Editor: E. Karapinar

Copyright (c) 2013 Sunny Chauhan et al. This is an open access article distributed under the Creative Commons Attribution License, which permits unrestricted use, distribution, and reproduction in any medium, provided the original work is properly cited.

\begin{abstract}
We prove a common fixed point theorem for two pairs of compatible and subsequentially continuous (alternately subcompatible and reciprocally continuous) mappings satisfying a general contractive condition in a metric space. Some illustrative examples are furnished to highlight the realized improvements. Our result improves the main result of Sedghi and Shobe (2007).
\end{abstract}

\section{Introduction}

Fixed point theory is one of the most fruitful and effective tools in mathematics which has enormous applications within as well as outside mathematics. Starting from the celebrated Banach contraction principle [1], many authors have obtained its several generalizations in different ways (see, e.g., [2-4]).

A metrical common fixed point theorem generally involves conditions on commutativity, continuity, and contraction of the given mappings, as well as completeness (or closedness) of the underlying space (or subspaces), along with conditions on suitable containment amongst the ranges of involved mappings. Hence, in order to prove a new metrical common fixed point theorem, one is always required to weaken one or more of these conditions. In order to weaken commutativity conditions in common fixed point theorems, Sessa [5] introduced the concept of weakly commuting mappings. Jungck [6] defined the notion of compatible mappings in order to generalize the concept of weak commutativity and showed that weakly commuting mappings are compatible, but the converse is not true. Afterwards Jungck and Rhoades [7] introduced the concept of weak compatibility to the setting of single-valued and multivalued mappings which is more general than compatibility. However, the study of common fixed points of noncompatible mappings is also equally interesting, and it was initiated by Pant [8] in metric spaces. Researchers of this domain introduced several definitions of weak commutativity such as compatible mappings, compatibility of type $(A),(B),(C)$, and $(P)$, and several others, whose systematic comparisons and illustrations are available in Murthy [9] and Singh and Tomar [10].

In 2002, Aamri and El Moutawakil [11] introduced the notion of property (E.A). Further, Al-Thagafi and Shahzad [12] introduced the notion of occasionally weakly compatible mappings. It was used further by many authors (see, e.g., [13]). However, in [14], Đorić et al. observed that the condition of occasionally weak compatibility reduces to weak compatibility in the presence of a unique point of coincidence of the given pair of mappings. Thus, no generalization can be obtained by replacing weak compatibility with occasionally weak compatibility (see also [15-17]).

In 2009, Bouhadjera and Godet-Thobie [18] further enlarged the class of compatible (reciprocally continuous) pairs by introducing the concept of subcompatibility (subsequential continuity) of pairs of mappings, which is substantially weaker than compatibility (reciprocal continuity). Since then, Imdad et al. [19] improved the results of Bouhadjera and Godet-Thobie and showed that these results can easily be recovered by replacing subcompatibility with compatibility 
or subsequential continuity with reciprocal continuity. Very recently, Chauhan et al. [20] obtained some results of this kind using integral type contractive conditions. Many authors established a number of other fixed point results in metric and related spaces (see, e.g., [21-31]).

In 2007, Sedghi and Shobe [32] proved a common fixed point theorem for weakly compatible mappings satisfying a new general contractive type condition. The aim of this paper is to prove a common fixed point theorem for two pairs of self-mappings by using the notions of compatibility and subsequential continuity (alternately subcompatibility and reciprocal continuity) satisfying general contractive condition in a metric space. Some examples are furnished which demonstrate the validity of our result.

\section{Preliminaries}

Definition 1. Let $A, S: X \rightarrow X$ be two self-mappings on a metric space $(X, d)$. The mappings $A$ and $S$ are said to be

(1) weakly commuting if $d(A S x, S A x) \leq d(A x, S x)$ for all $x \in X[5]$,

(2) compatible if $\lim _{n \rightarrow \infty} d\left(A S x_{n}, S A x_{n}\right)=0$ for each sequence $\left\{x_{n}\right\}$ in $X$ such that $\lim _{n \rightarrow \infty} A x_{n}=$ $\lim _{n \rightarrow \infty} S x_{n}[6]$,

(3) noncompatible if there exists a sequence $\left\{x_{n}\right\}$ in $X$ such that $\lim _{n \rightarrow \infty} A x_{n}=\lim _{n \rightarrow \infty} S x_{n}$, but $\lim _{n \rightarrow \infty} d\left(A S x_{n}, S A x_{n}\right)$ is either nonzero or nonexistent $[8]$,

(4) weakly compatible if they commute at their coincidence points; that is, $A S u=S A u$ whenever $A u=S u$, for some $u \in X$ [7],

(5) occasionally weakly compatible if there is a point $x \in$ $X$ which is a coincidence point of $A$ and $S$ at which $A$ and $S$ commute [12],

(6) with the property (E.A) if there exists a sequence $\left\{x_{n}\right\}$ in $X$ and some $z \in X$ such that $\lim _{n \rightarrow \infty} A x_{n}=$ $\lim _{n \rightarrow \infty} S x_{n}=z[11]$.

It can be noticed that arbitrary noncompatible selfmappings satisfy the property (E.A) but two mappings satisfying the property (E.A), need not be noncompatible (see [33, Example 1]). Also, weak compatibility and property (E.A) are independent of each other (see [31, Examples 2.1 and 2.2]).

Definition 2 (see [34]). A pair $(A, S)$ of self-mappings on a metric space $(X, d)$ is called reciprocally continuous if for a sequence $\left\{x_{n}\right\}$ in $X, \lim _{n \rightarrow \infty} A S x_{n}=A z$ and $\lim _{n \rightarrow \infty} S A x_{n}=$ $S z$, whenever $\lim _{n \rightarrow \infty} A x_{n}=\lim _{n \rightarrow \infty} S x_{n}=z$, for some $z \in$ $X$.

It is easy to see that if two self-mappings are continuous, then they are obviously reciprocally continuous, but the converse is not true. Moreover, in the setting of common fixed point theorems for compatible pairs of self-mappings satisfying contractive conditions, continuity of one of the mappings implies their reciprocal continuity but not conversely (see [35]).
Definition 3 (see [18]). A pair $(A, S)$ of self-mappings on a metric space $(X, d)$ is said to be subcompatible if there exists a sequence $\left\{x_{n}\right\}$ such that $\lim _{n \rightarrow \infty} A x_{n}=\lim _{n \rightarrow \infty} S x_{n}=z$, for some $z \in X$ and $\lim _{n \rightarrow \infty} d\left(A S x_{n}, S A x_{n}\right)=0$.

A pair of subcompatible mappings satisfies the property (E.A). Obviously, compatible mappings which satisfy the property (E.A) are subcompatible, but the converse statement does not hold in general (see [36, Example 2.3]). Two occasionally weakly compatible mappings are subcompatible; however, the converse is not true in general (see [18, Example $1.2])$.

Definition 4 (see [18]). A pair $(A, S)$ of self-mappings on a metric space $(X, d)$ is called subsequentially continuous if there exists a sequence $\left\{x_{n}\right\}$ in $X$ such that $\lim _{n \rightarrow \infty} A x_{n}=$ $\lim _{n \rightarrow \infty} S x_{n}=z$, for some $z \in X$ such that $\lim _{n \rightarrow \infty} A S x_{n}=$ $A z$ and $\lim _{n \rightarrow \infty} S A x_{n}=S z$.

One can easily check that if two self-mappings $A$ and $S$ are both continuous, hence also reciprocally continuous mappings but $A$ and $S$ are not subsequentially continuous (see [35, Example 1]).

Definition 5 (see [32]). By $\diamond: \mathbb{R}^{+} \times \mathbb{R}^{+} \rightarrow \mathbb{R}^{+}$, a binary operation will be denoted, satisfying the following conditions:

(1) $\diamond$ is associative and commutative,

(2) $\diamond$ is continuous.

Some typical examples of $\diamond$ are $a \diamond b=\max \{a, b\}, a \diamond b=$ $a+b, a \diamond b=a b, a \diamond b=a b+a+b$, and $a \diamond b=a b / \max \{a, b, 1\}$, for each $a, b \in \mathbb{R}^{+}$.

Definition 6 (see [32]). The binary operation $\diamond$ is said to satisfy $\alpha$-property if there exists a positive real number $\alpha$ such that

$$
a \diamond b \leq \alpha \max \{a, b\},
$$

for all $a, b \in \mathbb{R}^{+}$.

Example 7 (see [32]). (1) If $a \diamond b=a+b$, for each $a, b \in \mathbb{R}^{+}$, then for $\alpha \geq 2$, we have $a \diamond b \leq \alpha \max \{a, b\}$.

(2) If $a \diamond b=a b / \max \{a, b, 1\}$, for each $a, b \in \mathbb{R}^{+}$, then for $\alpha \geq 1$, we have $a \diamond b \leq \alpha \max \{a, b\}$.

\section{Main Results}

In 2007, Sedghi and Shobe [32] proved the following result.

Theorem 8 (see [32, Theorem 2.1]). Let $(X, d)$ be a complete metric space such that $\diamond$ satisfies the $\alpha$-property with $\alpha>0$. Let $A, B, S$, and $T$ be self-mappings on $X$ satisfying the following conditions:

(1) $A(X) \subseteq T(X), B(X) \subseteq S(X)$, and $T(X)$ or $S(X)$ is a closed subset of $X$,

(2) the pairs $(A, S)$ and $(B, T)$ are weakly compatible, 
(3) for all $x, y \in X$,

$$
\begin{aligned}
d(A x, B y) \leq & k_{1}(d(S x, T y) \diamond d(A x, S x)) \\
& +k_{2}(d(S x, T y) \diamond d(B y, T y)) \\
& +k_{3}\left(d(S x, T y) \diamond \frac{d(S x, B y)+d(A x, T y)}{2}\right),
\end{aligned}
$$

where $k_{1}, k_{2}, k_{3}>0$ and $0<\alpha\left(k_{1}+k_{2}+k_{3}\right)<1$.

Then, $A, B, S$, and $T$ have a unique common fixed point in $X$.

Now we prove our main result.

Theorem 9. Let $A, B, S$, and $T$ be four self-mappings on a metric space $(X, d)$, and let the operation $\diamond$ satisfy the $\alpha$-property with $\alpha>0$. Suppose that the pairs $(A, S)$ and $(B, T)$ are compatible and subsequentially continuous (alternately subcompatible and reciprocally continuous), satisfying inequality (2) of Theorem 8. Then $A, B, S$, and T have a unique common fixed point in $X$.

Proof. If the pair of mappings $(A, S)$ is subsequentially continuous and compatible, there exists a sequence $\left\{x_{n}\right\}$ in $X$ such that

$$
\lim _{n \rightarrow \infty} A x_{n}=\lim _{n \rightarrow \infty} S x_{n}=z
$$

for some $z \in X$, and

$$
\lim _{n \rightarrow \infty} d\left(A S x_{n}, S A x_{n}\right)=d(A z, S z)=0
$$

that is, $A z=S z$. Similarly, with respect to the pair $(B, T)$, there exists a sequence $\left\{y_{n}\right\}$ in $X$ such that

$$
\lim _{n \rightarrow \infty} B y_{n}=\lim _{n \rightarrow \infty} T y_{n}=w,
$$

for some $w \in X$, and

$$
\lim _{n \rightarrow \infty} d\left(B T y_{n}, T B y_{n}\right)=d(B w, T w)=0 ;
$$

that is, $B w=T w$. Hence $z$ is a coincidence point of the pair $(A, S)$ whereas $w$ is a coincidence point of the pair $(B, T)$.

Now we assert that $z=w$. If $z \neq w$ then using inequality (2) with $x=x_{n}$ and $y=y_{n}$, we have

$$
\begin{aligned}
& d\left(A x_{n}, B y_{n}\right) \\
& \leq k_{1}\left(d\left(S x_{n}, T y_{n}\right) \diamond d\left(A x_{n}, S x_{n}\right)\right) \\
&+k_{2}\left(d\left(S x_{n}, T y_{n}\right) \diamond d\left(B y_{n}, T y_{n}\right)\right) \\
&+k_{3}\left(d\left(S x_{n}, T y_{n}\right) \diamond \frac{d\left(S x_{n}, B y_{n}\right)+d\left(A x_{n}, T y_{n}\right)}{2}\right) .
\end{aligned}
$$

Letting $n \rightarrow \infty$, we get

$$
\begin{aligned}
d(z, w) \leq & k_{1}(d(z, w) \diamond d(z, z)) \\
& +k_{2}(d(z, w) \diamond d(w, w)) \\
& +k_{3}\left(d(z, w) \diamond \frac{d(z, w)+d(z, w)}{2}\right) .
\end{aligned}
$$

Since $\diamond$ satisfies the $\alpha$-property, we obtain

$$
\begin{aligned}
d(z, w) \leq & k_{1} \alpha \max \{d(z, w), d(z, z)\} \\
& +k_{2} \alpha \max \{d(z, w), d(w, w)\} \\
& +k_{3} \alpha \max \left\{d(z, w), \frac{d(z, w)+d(z, w)}{2}\right\} \\
= & k_{1} \alpha \max \{d(z, w), 0\}+k_{2} \alpha \max \{d(z, w), 0\} \\
& +k_{3} \alpha \max \{d(z, w), d(z, w)\} \\
= & \alpha\left(k_{1}+k_{2}+k_{3}\right) d(z, w) \\
< & d(z, w),
\end{aligned}
$$

which is a contradiction. Hence $z=w$. Now we prove that $A z=z$. If we suppose that $A z \neq z$, then from inequality (2) with $x=z$ and $y=y_{n}$, we have

$$
\begin{aligned}
d\left(A z, B y_{n}\right) & \\
\leq & k_{1}\left(d\left(S z, T y_{n}\right) \diamond d(A z, S z)\right) \\
& +k_{2}\left(d\left(S z, T y_{n}\right) \diamond d\left(B y_{n}, T y_{n}\right)\right) \\
& +k_{3}\left(d\left(S z, T y_{n}\right) \diamond \frac{d\left(S z, B y_{n}\right)+d\left(A z, T y_{n}\right)}{2}\right) .
\end{aligned}
$$

Taking the limit as $n \rightarrow \infty$, we get

$$
\begin{aligned}
d(A z, w) \leq & k_{1}(d(S z, w) \diamond d(A z, A z)) \\
& +k_{2}(d(A z, w) \diamond d(w, w)) \\
& +k_{3}\left(d(A z, w) \diamond \frac{d(A z, w)+d(A z, w)}{2}\right) ;
\end{aligned}
$$

that is,

$$
\begin{aligned}
d(A z, z) \leq & k_{1}(d(S z, z) \diamond d(A z, A z)) \\
& +k_{2}(d(A z, z) \diamond d(z, z)) \\
& +k_{3}\left(d(A z, z) \diamond \frac{d(A z, z)+d(A z, z)}{2}\right) \\
\leq & k_{1} \alpha \max \{d(S z, z), d(A z, A z)\} \\
& +k_{2} \alpha \max \{d(A z, z), d(z, z)\} \\
& +k_{3} \alpha \max \left\{d(A z, z), \frac{d(A z, z)+d(A z, z)}{2}\right\} .
\end{aligned}
$$

Then, simplifying, we obtain

$$
\begin{aligned}
d(A z, z) & \leq \alpha\left(k_{1}+k_{2}+k_{3}\right) d(A z, z) \\
& <d(A z, z),
\end{aligned}
$$


a contradiction. Hence, $A z=z$. Therefore, $A z=S z=z$. Now we show that $B z=z$. If $B z \neq z$ then using (2) with $x=x_{n}$ and $y=z$, we have

$$
\begin{aligned}
d\left(A x_{n}, B z\right) & \\
\leq & k_{1}\left(d\left(S x_{n}, T z\right) \diamond d\left(A x_{n}, S x_{n}\right)\right) \\
& +k_{2}\left(d\left(S x_{n}, T z\right) \diamond d(B z, T z)\right) \\
& +k_{3}\left(d\left(S x_{n}, T z\right) \diamond \frac{d\left(S x_{n}, B z\right)+d\left(A x_{n}, T z\right)}{2}\right) .
\end{aligned}
$$

As $n \rightarrow \infty$, we get

$$
\begin{aligned}
d(z, B z) \leq & k_{1}(d(z, B z) \diamond d(z, z)) \\
& +k_{2}(d(z, B z) \diamond d(B z, B z)) \\
& +k_{3}\left(d(z, B z) \diamond \frac{d(z, B z)+d(z, B z)}{2}\right) \\
\leq & k_{1} \alpha \max \{d(z, B z), d(z, z)\} \\
& +k_{2} \alpha \max \{d(z, B z), d(B z, B z)\} \\
& +k_{3} \alpha \max \left\{d(z, B z), \frac{d(z, B z)+d(z, B z)}{2}\right\} .
\end{aligned}
$$

Then, simplifying, we obtain

$$
\begin{aligned}
d(z, B z) & \leq \alpha\left(k_{1}+k_{2}+k_{3}\right) d(z, B z) \\
& <d(z, B z)
\end{aligned}
$$

a contradiction. Hence, $B z=z$. Therefore, $z=A z=S z=$ $B z=T z$; that is, $z$ is a common fixed point of $A, B, S$, and $T$. The uniqueness of common fixed point is an easy consequence of inequality (2).

Now suppose that the mappings $(A, S)$ (as well as $(B, T)$ ) are subcompatible and reciprocally continuous. Then there exists a sequence $\left\{x_{n}\right\}$ in $X$ such that

$$
\lim _{n \rightarrow \infty} A x_{n}=\lim _{n \rightarrow \infty} S x_{n}=z
$$

for some $z \in X$, and

$$
\lim _{n \rightarrow \infty} d\left(A S x_{n}, S A x_{n}\right)=d(A z, S z)=0
$$

whereas in respect of the pair $(B, T)$, there exists a sequence $\left\{y_{n}\right\}$ in $X$ with

$$
\lim _{n \rightarrow \infty} B y_{n}=\lim _{n \rightarrow \infty} T y_{n}=w
$$

for some $w \in X$, and

$$
\lim _{n \rightarrow \infty} d\left(B T y_{n}, T B y_{n}\right)=d(B w, T w)=0 .
$$

Therefore, $A z=S z$ and $B w=T w$; that is, $z$ is a coincidence point of the pair $(A, S)$ whereas $w$ is a coincidence point of the pair $(B, T)$. The rest of the proof can be completed easily.
Example 10. Let $X=[0, \infty)$, and let $d$ be the usual metric on $X$. Define self-mappings $A, B, S$, and $T$ by

$$
\begin{aligned}
& A x=B x= \begin{cases}\frac{x}{7}, & \text { if } x \in[0,1] ; \\
\frac{x+6}{7}, & \text { if } x \in(1, \infty),\end{cases} \\
& S x=T x= \begin{cases}\frac{x}{6}, & \text { if } x \in[0,1] ; \\
\frac{x+5}{6}, & \text { if } x \in(1, \infty) .\end{cases}
\end{aligned}
$$

Consider the sequence $\left\{x_{n}\right\}=\{1 / n\}_{n \in \mathbb{N}}$ in $X$. Then

$$
\lim _{n \rightarrow \infty} A x_{n}=\lim _{n \rightarrow \infty} \frac{1}{7 n}=0=\lim _{n \rightarrow \infty} \frac{1}{6 n}=\lim _{n \rightarrow \infty} S x_{n} .
$$

Next,

$$
\begin{gathered}
\lim _{n \rightarrow \infty} A S x_{n}=\lim _{n \rightarrow \infty} A\left(\frac{1}{6 n}\right)=\lim _{n \rightarrow \infty} \frac{1}{42 n}=0=A 0, \\
\lim _{n \rightarrow \infty} S A x_{n}=\lim _{n \rightarrow \infty} S\left(\frac{1}{7 n}\right)=\lim _{n \rightarrow \infty} \frac{1}{42 n}=0=S 0, \\
\lim _{n \rightarrow \infty} d\left(A S x_{n}, S A x_{n}\right)=0 .
\end{gathered}
$$

Consider another sequence $\left\{x_{n}\right\}=\{1+1 / n\}_{n \in \mathbb{N}}$ in $X$. Then

$$
\begin{aligned}
\lim _{n \rightarrow \infty} A x_{n} & =\lim _{n \rightarrow \infty}\left(1+\frac{1}{7 n}\right)=1 \\
& =\lim _{n \rightarrow \infty}\left(1+\frac{1}{6 n}\right)=\lim _{n \rightarrow \infty} S x_{n} .
\end{aligned}
$$

However,

$$
\begin{aligned}
& \lim _{n \rightarrow \infty} A S x_{n}=\lim _{n \rightarrow \infty} A\left(1+\frac{1}{6 n}\right)=\lim _{n \rightarrow \infty}\left(1+\frac{1}{42 n}\right)=1 \neq A 1, \\
& \lim _{n \rightarrow \infty} S A x_{n}=\lim _{n \rightarrow \infty} S\left(1+\frac{1}{7 n}\right)=\lim _{n \rightarrow \infty}\left(1+\frac{1}{42 n}\right)=1 \neq S 1,
\end{aligned}
$$

but $\lim _{n \rightarrow \infty} d\left(A S x_{n}, S A x_{n}\right)=0$. Thus, the pair $(A, S)$ is compatible as well as subsequentially continuous but not reciprocally continuous (the same for the pair $(B, T)$ ). It is easy to check that condition (2) is satisfied with $\diamond=\max , \alpha=$ 1 , and $k_{1}+k_{2}+k_{3}=6 / 7$. Therefore, all the conditions of Theorem 9 are satisfied. Here, 0 is a coincidence as well as the unique common fixed point of the mappings $A, B, S$, and $T$.

It can be noted that this example cannot be covered by those fixed point theorems which assume both compatibility and reciprocal continuity or by involving conditions of closedness of respective ranges. Indeed, in this example $A(X)=[0,1 / 7] \cup(1, \infty)$ and $S(X)=[0,1 / 6] \cup(1, \infty)$; hence, neither of $A(X)$ and $S(X)$ is closed.

Example 11. Let $X=\mathbb{R}$ (set of real numbers), and let $d$ be the usual metric on $X$. Define self-mappings $A, B, S$, and $T$ by

$$
\begin{aligned}
& A x=B x= \begin{cases}\frac{x}{4}, & \text { if } x \in(-\infty, 1) ; \\
4 x-3, & \text { if } x \in[1, \infty),\end{cases} \\
& S x=T x= \begin{cases}x+3, & \text { if } x \in(-\infty, 1) ; \\
5 x-4, & \text { if } x \in[1, \infty) .\end{cases}
\end{aligned}
$$


Consider the sequence $\left\{x_{n}\right\}=\{1+1 / n\}_{n \in \mathbb{N}}$ in $X$. Then

$$
\begin{aligned}
\lim _{n \rightarrow \infty} A x_{n} & =\lim _{n \rightarrow \infty}\left(1+\frac{4}{n}\right)=1 \\
& =\lim _{n \rightarrow \infty}\left(1+\frac{5}{n}\right)=\lim _{n \rightarrow \infty} S x_{n} .
\end{aligned}
$$

Also,

$$
\begin{gathered}
\lim _{n \rightarrow \infty} A S x_{n}=\lim _{n \rightarrow \infty} A\left(1+\frac{5}{n}\right)=\lim _{n \rightarrow \infty}\left(1+\frac{20}{n}\right)=1=A 1, \\
\lim _{n \rightarrow \infty} S A x_{n}=\lim _{n \rightarrow \infty} S\left(1+\frac{4}{n}\right)=\lim _{n \rightarrow \infty}\left(1+\frac{20}{n}\right)=1=S 1, \\
\lim _{n \rightarrow \infty} d\left(A S x_{n}, S A x_{n}\right)=0 .
\end{gathered}
$$

Consider another sequence $\left\{x_{n}\right\}=\{(1 / n)-4\}_{n \in \mathbb{N}}$ in $X$. Then

$$
\begin{aligned}
\lim _{n \rightarrow \infty} A\left(x_{n}\right) & =\lim _{n \rightarrow \infty}\left(\frac{1}{4 n}-1\right)=-1 \\
& =\lim _{n \rightarrow \infty}\left(\frac{1}{n}-1\right)=\lim _{n \rightarrow \infty} S\left(x_{n}\right) .
\end{aligned}
$$

Next,

$$
\begin{aligned}
\lim _{n \rightarrow \infty} A S x_{n} & =\lim _{n \rightarrow \infty} A\left(\frac{1}{n}-1\right) \\
& =\lim _{n \rightarrow \infty}\left(\frac{1}{4 n}-\frac{1}{4}\right)=-\frac{1}{4}=A(-1), \\
\lim _{n \rightarrow \infty} S A x_{n} & =\lim _{n \rightarrow \infty} S\left(\frac{1}{4 n}-1\right) \\
& =\lim _{n \rightarrow \infty}\left(\frac{1}{4 n}-1+3\right)=2=S(-1),
\end{aligned}
$$

and $\lim _{n \rightarrow \infty} d\left(A S x_{n}, S A x_{n}\right) \neq 0$. Thus, the pair $(A, S)$ is reciprocally continuous as well as subcompatible but not compatible (the same for the pair $(B, T)$ ). It is easy to check that condition (2) is satisfied with $\diamond=\max , \alpha=1$, and $k_{1}+$ $k_{2}+k_{3}=4 / 5$. Therefore, all the conditions of Theorem 9 are satisfied. Thus, 1 is a coincidence as well as the unique common fixed point of the pair $(A, S)$.

It can be noted that this example cannot be covered by those fixed point theorems which involve both compatibility and reciprocal continuity. Again, $A(X)=(-\infty, 1 / 4) \cup$ $[1,+\infty)$ is not closed. Note also that the mappings $A$ and $S$ have two points of coincidence $(-1$ and 1$)$, which are occasionally weakly compatible but not weakly compatible.

In the next example (taken from [18, Example 1.4]), we demonstrate the situation when conditions of Theorem 9 are not satisfied, and the given pairs have no common fixed points.
Example 12. Let $X=[0,+\infty)$ with the standard metric $d$, and let $A, B, S, T: X \rightarrow X$ be given by

$$
\begin{aligned}
& A x=B x= \begin{cases}x+1, & 0 \leq x \leq 1, \\
2 x-1, & x>1,\end{cases} \\
& S x=T x= \begin{cases}1-x, & 0 \leq x<1, \\
3 x-2, & x \geq 1 .\end{cases}
\end{aligned}
$$

Then, as it was shown in [18, Example 1.4], the pairs $(A, S)$ and $(B, T)$ are subsequentially continuous and subcompatible. However, they are neither reciprocally continuous nor compatible (not even occasionally weakly compatible). We note that $(A, S)$ has no common fixed points, although it has a unique point of coincidence $z=1$.

We present an example of different kind, inspired by [20, Example 3].

Example 13. Let $X=\{0,1,2, \ldots, 10\}$, and define a metric $d$ on $X$ by

$$
d(x, y)= \begin{cases}0, & x=y, \\ \max \{x, y\}, & x \neq y .\end{cases}
$$

Consider the mappings $A, B, S, T: X \rightarrow X$ given by

$$
\begin{gathered}
A x=B x= \begin{cases}0, & x=0 \\
x-1, & x \geq 1\end{cases} \\
S x=T x= \begin{cases}0, & x=0 \\
x+1, & 1 \leq x \leq 9, \\
10, & x=10\end{cases}
\end{gathered}
$$

Take $\diamond=\max$ (which satisfies $\alpha$-condition with $\alpha=1$ ). Then,

(1) the pair $(A, S)$ (as well as $(B, T))$ is compatible and subsequentially continuous,

(2) condition (2) is satisfied with $k_{1}=k_{2}=k_{3}=0.3$.

Indeed, in order to prove (1), take $x_{n}=0$ for all $n$ but finitely many (which is the only possibility to obtain the same limit for $\left(A x_{n}\right)$ and $\left.\left(S x_{n}\right)\right)$. Then $d\left(A x_{n}, 0\right) \rightarrow 0$ and $d\left(S x_{n}, 0\right) \rightarrow$ 0 ; also $S A x_{n} \rightarrow 0=S 0$ and $A S x_{n} \rightarrow 0=A 0$. Hence, the pair $(A, S)$ is compatible and subsequentially continuous.

In order to prove (2), suppose that $x, y \in X, x \neq y$ (the case $x=y$ is trivial). Since we have $A=B, S=T$, and $k_{1}=$ $k_{2}$, condition (2) is symmetric in $x, y$; hence, without loss of generality, we can suppose that $x \geq y$. Consider the following possible cases. 
Case 1. One has $y=0$ and $x=1$. Then $A x=B y=0, d(A x$, $B y)=0$, and (2) is satisfied.

Case 2. One has $y \in\{0,1\}$ and $2 \leq x \leq 9$. Then $A x=x-1$, $B y=0, d(A x, B y)=x-1$. The right-hand side of (2) becomes $(t \in\{0,2\})$

$$
\begin{aligned}
R= & k_{1} \max \{x+1, t\}+k_{2} \max \{x+1, x+1\} \\
& +k_{3} \max \left\{x+1, \frac{1}{2}[\max \{S x, B y\}+x+1]\right\} \\
= & \left(k_{1}+k_{2}+k_{3}\right)(x+1)=0.9(x+1) \\
\geq & 0.9 \cdot \frac{10}{8}(x-1)>x-1=d(A x, B y) .
\end{aligned}
$$

Case 3. One has $y \in\{0,1\}$ and $x=10$. Then

$$
d(A x, B y)=9=\left(k_{1}+k_{2}+k_{3}\right) \cdot 10=R .
$$

Case 4. One has $2 \leq y<x \leq 9$. Then $d(A x, B y)=d(x-$ $1, y-1)=x-1$ and

$$
\begin{aligned}
R= & k_{1} \max \{x+1, x+1\}+k_{2} \max \{x+1, y+1\} \\
& +k_{3} \max \left\{x+1, \frac{1}{2}[x+1+\max \{A x, T y\}]\right\} \\
= & \left(k_{1}+k_{2}+k_{3}\right)(x+1)=0.9(x+1) \\
\geq & 0.9 \cdot \frac{10}{8}(x-1)>x-1=d(A x, B y) .
\end{aligned}
$$

Case 5. One has $2 \leq y<x=10$. Then (2) again reduces to $9=\left(k_{1}+k_{2}+k_{3}\right) \cdot 10$.

All the conditions of Theorem 9 are satisfied, and $A, B, S$, and $T$ have a unique common fixed point (which is $z=0$ ).

By choosing $A, B, S$, and $T$ suitably in Theorem 9, we can deduce corollaries for two or three self-mappings. As a sample, we deduce the following corollary for two self-mappings.

Corollary 14. Let $A$ and $S$ be two self-mappings on a metric space $(X, d)$ such that $\diamond$ satisfies the $\alpha$-property with $\alpha>0$. If the pair $(A, S)$ is compatible and subsequentially continuous (alternately subcompatible and reciprocally continuous) satisfying

$$
\begin{aligned}
d(A x, A y) \leq & k_{1}(d(S x, S y) \diamond d(A x, S x)) \\
& +k_{2}(d(S x, S y) \diamond d(A y, S y)) \\
& +k_{3}\left(d(S x, S y) \diamond \frac{d(S x, A y)+d(A x, S y)}{2}\right),
\end{aligned}
$$

for all $x, y \in X$, where $k_{1}, k_{2}, k_{3}>0$ and $0<\alpha\left(k_{1}+k_{2}+k_{3}\right)<1$, then $A$ and $S$ have a unique common fixed point in $X$.
Remark 15. The conclusion of Theorem 9 remains true if we replace inequality (2) by the following:

$$
\begin{aligned}
d(A x, B y) \leq & k_{1}(d(S x, T y)+d(A x, S x)) \\
& +k_{2}(d(S x, T y)+d(B y, T y)) \\
& +k_{3}\left(d(S x, T y)+\frac{d(S x, B y)+d(A x, T y)}{2}\right),
\end{aligned}
$$

for all $x, y \in X$, where $k_{1}, k_{2}, k_{3}>0$ and $0<k_{1}+k_{2}+k_{3}<1 / 2$.

Similarly, other variants of contractive condition can be obtained by specifying operation $\diamond$.

Remark 16. Similar results can be obtained if condition (2) is replaced by the following one:

$$
\begin{aligned}
& d(A x, B y) \leq \psi(u) \\
& \text { for some } u \in\{d(S x, T y), d(A x, S x), \\
& \qquad d(B y, T y), d(S x, B y), \\
& d(A x, T y)\},
\end{aligned}
$$

for a suitable function $\psi:[0,+\infty) \rightarrow[0,+\infty)$.

\section{Conclusion}

Theorem 9 is proved for two pairs of compatible and subsequentially continuous (alternately subcompatible and reciprocally continuous) mappings satisfying a general contractive condition. Theorem 9 improves the main result of Sedghi and Shobe [32, Theorem 2.1] as we do not require any condition on the containment of ranges of involved mappings and completeness (or closedness) of the whole space (or any subspace). A natural result is defined in the form of a corollary (see Corollary 14). On the other hand, Remark 15 is developed for a particular case, $a \diamond b=a+b$, which also improves the result of Sedghi and Shobe [32, Corollary 2.2].

\section{Acknowledgments}

The authors would like to thank Professor Mohammad Imdad for the preprint of paper [36] and anonymous referees for their valuable comments that helped them to improve the exposition, in particular for Remark 16. The second author is thankful to the Ministry of Education, Science and Technological Development of Serbia.

\section{References}

[1] S. Banach, "Sur les opérations dans les ensembles abstraits et leur application aux équations intégrales," Fundamenta Mathematicae, vol. 3, no. 1, pp. 133-181, 1922.

[2] L. B. Ćirić, "On a family of contractive maps and fixed points," Publications de l'Institut Mathématique, vol. 17, no. 31, pp. 45-51, 1974.

[3] Lj. B. Cirić, "A generalization of Banach's contraction principle," Proceedings of the American Mathematical Society, vol. 45, pp. 267-273, 1974. 
[4] B. E. Rhoades, "A comparison of various definitions of contractive mappings," Transactions of the American Mathematical Society, vol. 226, pp. 257-290, 1977.

[5] S. Sessa, "On a weak commutativity condition of mappings in fixed point considerations," Publications de l'Institut Mathématique, vol. 32, no. 46, pp. 149-153, 1982.

[6] G. Jungck, "Compatible mappings and common fixed points," International Journal of Mathematics and Mathematical Sciences, vol. 9, no. 4, pp. 771-779, 1986.

[7] G. Jungck and B. E. Rhoades, "Fixed points for set valued functions without continuity," Indian Journal of Pure and Applied Mathematics, vol. 29, no. 3, pp. 227-238, 1998.

[8] R. P. Pant, "Noncompatible mappings and common fixed points," Soochow Journal of Mathematics, vol. 26, no. 1, pp. 2935, 2000.

[9] P. P. Murthy, "Important tools and possible applications of metric fixed point theory," Nonlinear Analysis, vol. 47, no. 5, pp. 3479-3490, 2001.

[10] S. L. Singh and A. Tomar, "Weaker forms of commuting maps and existence of fixed points," Journal of the Korean Society of Mathematical Education B, vol. 10, no. 3, pp. 145-161, 2003.

[11] M. Aamri and D. El Moutawakil, "Some new common fixed point theorems under strict contractive conditions," Journal of Mathematical Analysis and Applications, vol. 270, no. 1, pp. 181188, 2002.

[12] M. A. Al-Thagafi and N. Shahzad, "Generalized I-nonexpansive selfmaps and invariant approximations," Acta Mathematica Sinica, vol. 24, no. 5, pp. 867-876, 2008.

[13] G. Jungck and B. E. Rhoades, "Fixed point theorems for occasionally weakly compatible mappings," Fixed Point Theory, vol. 7, no. 2, pp. 287-296, 2006.

[14] D. Đorić, Z. Kadelburg, and S. Radenović, "A note on occasionally weakly compatible mappings and common fixed points," Fixed Point Theory, vol. 13, no. 2, pp. 475-479, 2012.

[15] M. A. Alghamdi, S. Radenović, and N. Shahzad, "On some generalizations of commuting mappings," Abstract and Applied Analysis, vol. 2012, Article ID 952052, 6 pages, 2012.

[16] R. K. Bisht and R. P. Pant, "A critical remark on "Fixed point theorems for occasionally weakly compatible mappings'”, Journal of the Egyptian Mathematical Society, 2013.

[17] R. K. Bisht and N. Shahzad, "Faintly compatible mappings and common fixed points," Fixed Point Theory and Applications, vol. 2013, article 156, 2013.

[18] H. Bouhadjera and C. Godet-Thobie, "Common fixed point theorems for pairs of subcompatible maps," old version, 2009, http://arxiv.org/abs/0906.3159.

[19] M. Imdad, J. Ali, and M. Tanveer, "Remarks on some recent metrical common fixed point theorems," Applied Mathematics Letters, vol. 24, no. 7, pp. 1165-1169, 2011.

[20] S. Chauhan, H. Aydi, W. Shatanawi, and C. Vetro, "Some integral type fixed point theorems and an application to system of functional equations," Vietnam Journal of Mathematics. In press.

[21] M. A. Ahmed, "Common fixed point theorems for weakly compatible mappings," The Rocky Mountain Journal of Mathematics, vol. 33, no. 4, pp. 1189-1203, 2003.

[22] M. Akkouchi, "Common fixed points for three mappings using G-functions and the property (E.A)," Acta Universitatis Apulensis, no. 23, pp. 223-231, 2010.

[23] M. Akkouchi, "A common fixed point theorem for four maps using a Lipschitz type condition," Mathematical Journal of the Ovidius University of Constantza, vol. 19, no. 3, pp. 17-26, 2011.
[24] H. Aydi and E. Karapinar, "A Meir-Keeler common type fixed point theorem on partial metric spaces," Fixed Point Theory and Applications, vol. 2012, article 26, 10 pages, 2012.

[25] I. Beg and M. Abbas, "Coincidence and common fixed points of noncompatiblemaps," Journal of Applied Mathematics \& Informatics, vol. 29, no. 3-4, pp. 743-752, 2011.

[26] R. Chugh and S. Kumar, "Common fixed points for weakly compatible maps," Proceedings of the Indian Academy of Sciences, vol. 111, no. 2, pp. 241-247, 2001.

[27] H. S. Ding, Z. Kadelburg, E. Karapınar, and S. Radenović, "Common fixed points of weak contractions in cone metric spaces," Abstract and Applied Analysis, vol. 2012, Article ID 793862, 18 pages, 2012.

[28] M. Imdad and S. Chauhan, "Employing common limit range property to prove unified metrical common fixed point theorems," International Journal of Analysis, vol. 2013, Article ID 763261, 10 pages, 2013.

[29] M. Imdad, S. Chauhan, and Z. Kadelburg, "Fixed point theorems for mappings with common limit range property satisfying generalized $(\psi, \phi)$-weak contractive conditions," Mathematical Sciences, vol. 7, article 16, 2013.

[30] E. Karapinar, N. Shobkolaei, S. Sedghi, and S. M. Vaezpour, "A common fixed point theorem for cyclic operators on partial metric spaces," Filomat, vol. 26, no. 2, pp. 407-414, 2012.

[31] H. K. Pathak, R. Rodríguez-López, and R. K. Verma, "A common fixed point theorem using implicit relation and property (E.A) in metric spaces," Filomat, vol. 21, no. 2, pp. 211-234, 2007.

[32] S. Sedghi and N. Shobe, "Common fixed point theorems for four mappings in complete metric spaces," Bulletin of the Iranian Mathematical Society, vol. 33, no. 2, pp. 37-47, 2007.

[33] J. X. Fang and Y. Gao, "Common fixed point theorems under strict contractive conditions in Menger spaces," Nonlinear Analysis, vol. 70, no. 1, pp. 184-193, 2009.

[34] R. P. Pant, "Common fixed points of Lipschitz type mapping pairs," Journal of Mathematical Analysis and Applications, vol. 240, no. 1, pp. 280-283, 1999.

[35] R. P. Pant and R. K. Bisht, "Common fixed point theorems under a new continuity condition," Annali dell'Universitá di Ferrara VII, vol. 58, no. 1, pp. 127-141, 2012.

[36] F. Rouzkard, M. Imdad, and H. K. Nashine, "New common fixed point theorems and invariant approximation in convex metric spaces," Bulletin of the Belgian Mathematical Society, vol. 19, no. 2, pp. 311-328, 2012. 


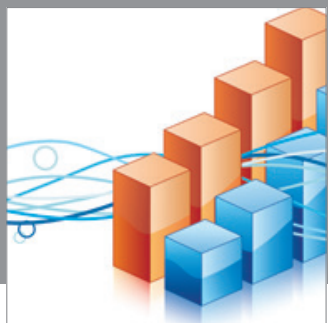

Advances in

Operations Research

mansans

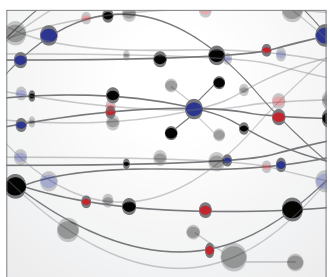

The Scientific World Journal
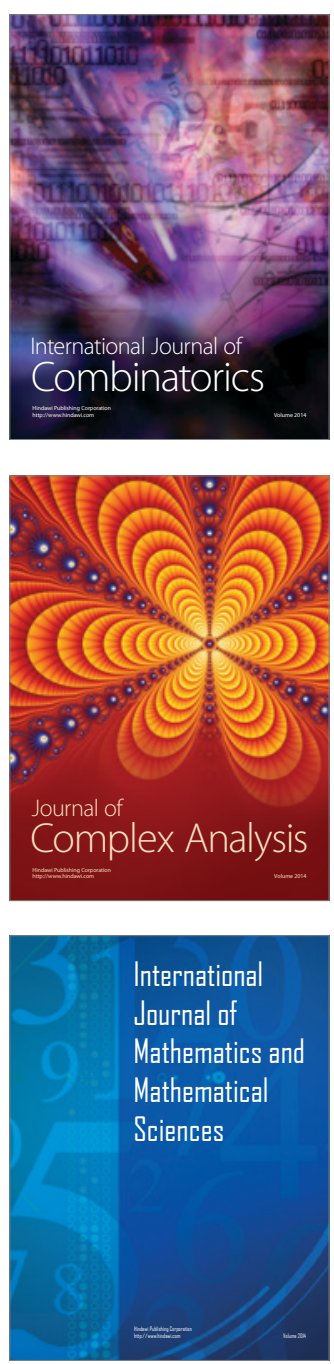
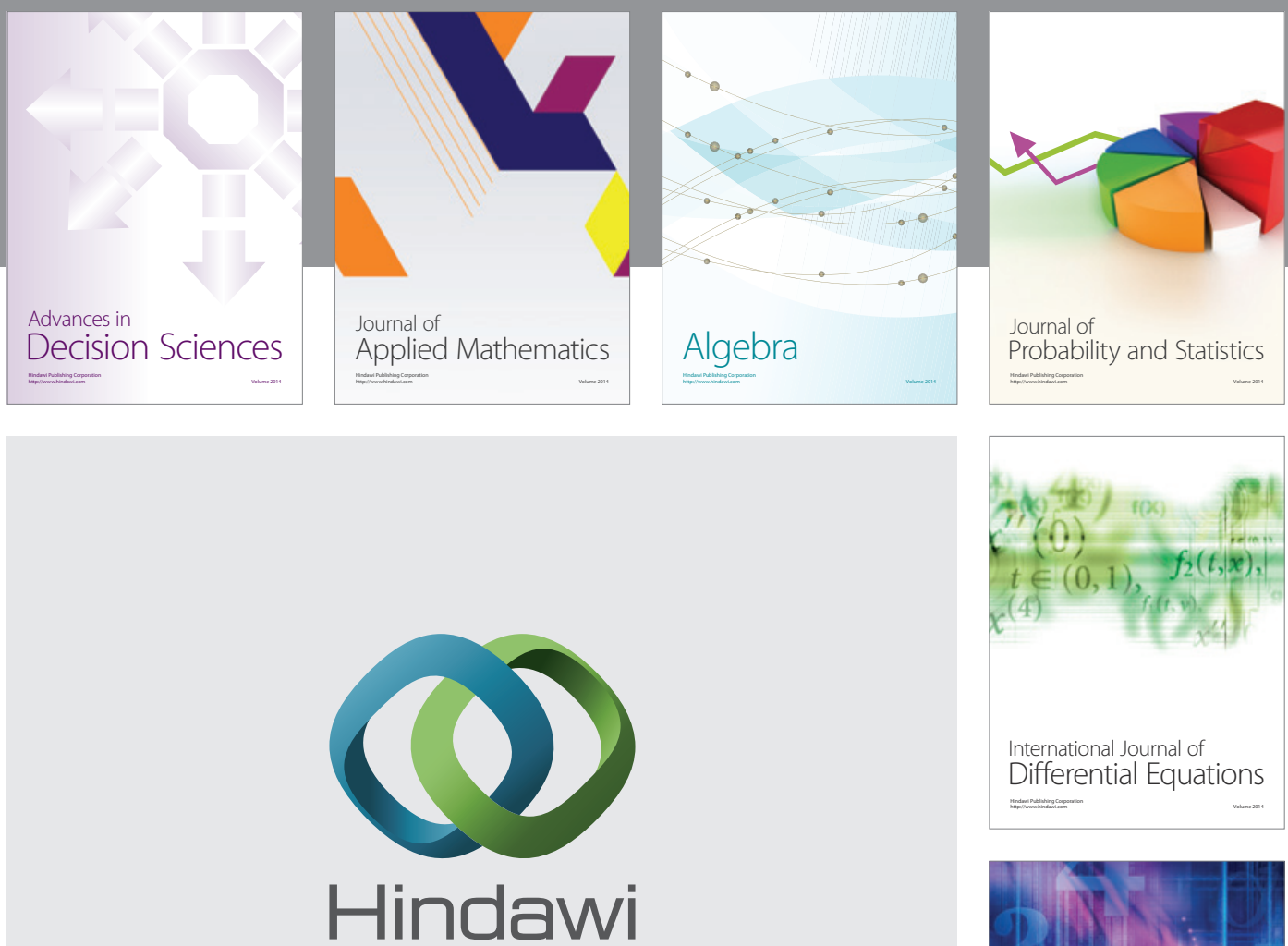

Submit your manuscripts at http://www.hindawi.com
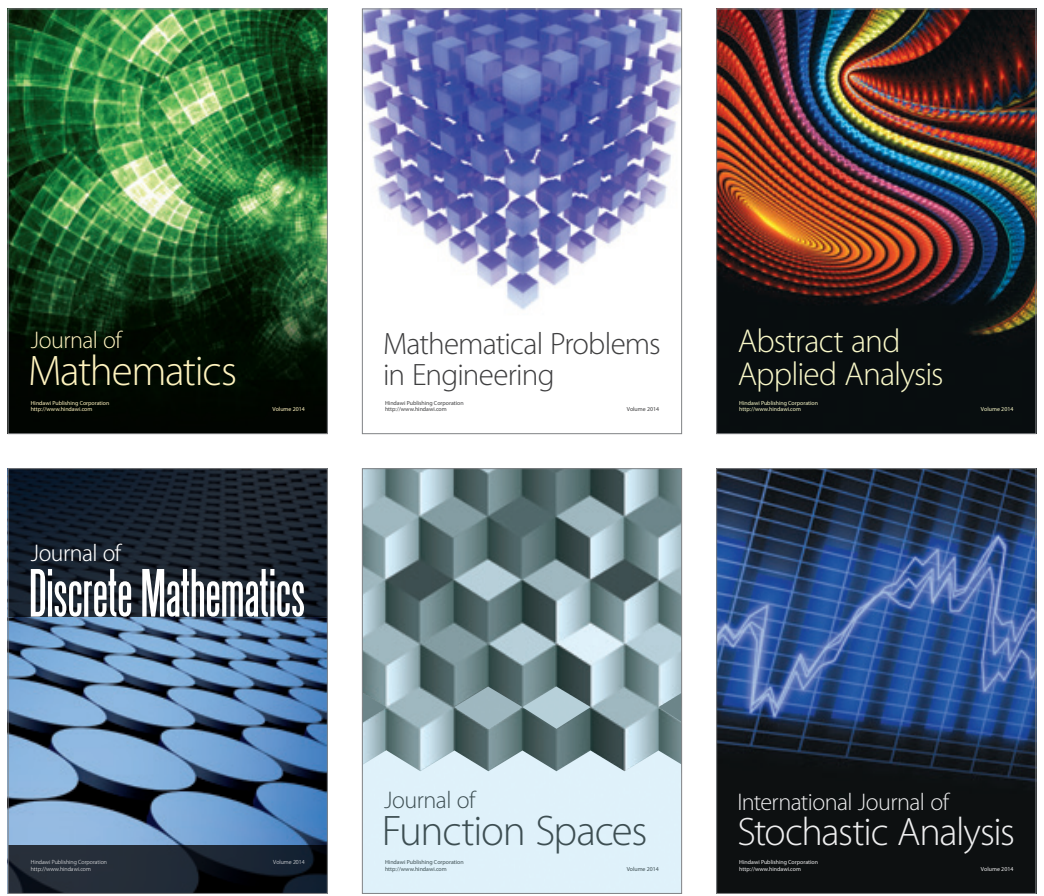

Journal of

Function Spaces

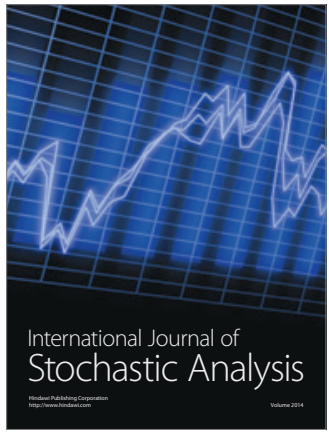

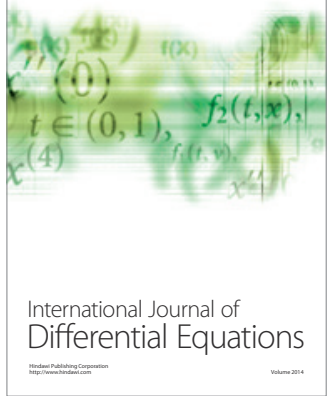
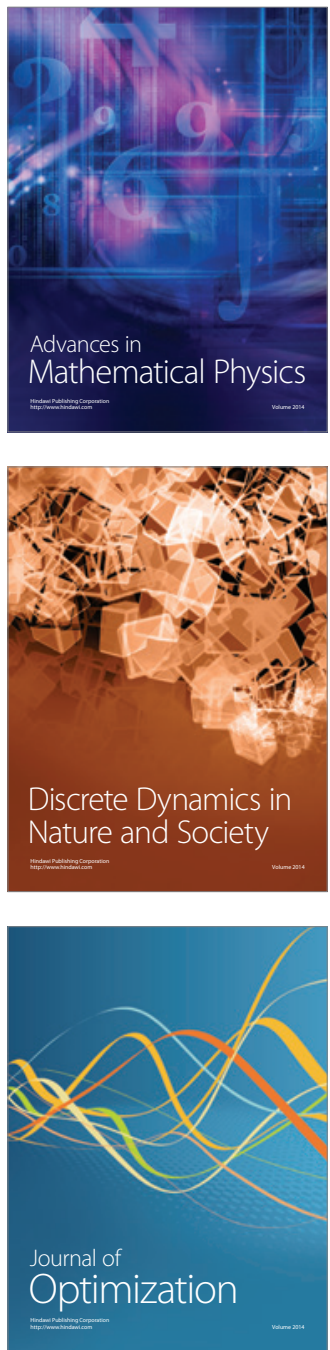